\title{
UTILIZATION OF THE HEALTH OPERATIONAL AID FOR THE COVERAGE OF MATERNAL HEALTH PROGRAM IN KENDARI, SOUTH EAST SULAWESI
}

\author{
Sija Tiku \\ Masters Program in Public Health, School of Health Sciences Mandala Waluya, Kendari
}

\begin{abstract}
Background: Maternal mortality rates vary significantly from region to region. Interventions such as early and planned antenatal care attendance and facility delivery with skilled health workers can potentially reduce maternal mortality rates. Several factors can be attributed to antenatal care attendance, including the cost of health care services. For several years the government has launched a financial assistant programe namely the health operational aid (BOK). However, there is a lack of information on how this fund has been utilized. The aim of this study was to describe utilization of the health operational aid for the coverage of maternal health program in Kendari, South East Sulawesi.

Subjects and Method: A qualitative study was carried out in Kendari, North Sulawesi. The informants included pregnant mothers, midwifes, and health personnel, at the community health center. The data were collected by in-depth interview, direct observation, focus group discussion (FGD), and document review.

Results: Maternal mortality rates in Kendari from 2013-2017 experienced fluctuations. In 2013 there were 6 maternal deaths, in 2014 there were 3 maternal deaths. In 2015 it rose to 8 maternal deaths, in 2016 it fell to 4 maternal deaths, and in 2017 it rose to 5 deaths. The coverage of childbirth assistance by health workers in Kendari continued to decline. In 2014 the coverage of childbirth was $95.31 \%$, in 2015 it dropped to $92.84 \%$, and in 2016 it decreased to $92.17 \%$. Inversely with health financing, the BOK fund in Kendari each year has increased. In 2014 the BOK amounted to Rp. 1,695,810,000, in 2015 Rp. 1,701,579,000, in $2016 \mathrm{Rp}$. 3,225,000,000, in 2017 Rp. 6,401,514,000 and in 2018 reached Rp. 8,319,751,000. The increased amount of BOK fund is not in line with the increase in coverage of deliveries by health workers, and there is no significant reduction in maternal mortality rates.

Conclusion: The increased amount of BOK fund does not match with the improvement in health care coverage. It is necessary to study the effectiveness and types of activities that use BOK funds in order to increase the coverage of services, especially delivery services by health workers to significantly reduce maternal mortality
\end{abstract}

Keywords: operational health assistance, coverage, maternal health, labor

\section{Correspondence:}

Sija Tiku. Masters Program in Public Health. School of Health Sciences, Mandala Waluya, Kendari, North Sulawesi. Email: sijahatiku@gmail.com. Mobile: o8114038140

The 5th International Conference on Public Health Best Western Premier Hotel, Solo, Indonesia, February 13-14, 2019 | 447 https://doi.org/10.26911/theicph.2019.04.23 